\title{
Factors Influencing Long-term Outcomes following Renal Transplantation: A Review
}

\author{
Shrestha BM, ${ }^{1}$ Haylor $\mathrm{JL}^{1}$ \\ ${ }^{1}$ Sheffield Kidney Institute, UK.
}

\begin{abstract}
Despite continuing advances in immunosuppressive and supportive therapies, the success of renal transplantation is impacted by factors present in the donor and recipient pre- and posttransplantation. The pre-transplant factors influencing the long-term graft function in the donor include source, age, sex, and HLA mismatches; and in the recipient include age, duration of dialysis and sensitisation. After transplantation, a number of events may lead to progressive deterioration of renal function and graft loss, which include delayed graft function, acute rejection, viral infections, recurrent disease, drug nephrotoxicity, non-compliance and chronic allograft nephropathy. Modulation of individual factor is mandatory to preserve satisfactory renal function in long-term. In this review, each factor is discussed in the context of current transplant practice and an up to date review of literature is presented.
\end{abstract}

Key words: Calcineurin inhibitors, Chronic allograft nephropathy, Long-term outcomes, Renal transplantation.

\section{INTRODUCTION}

Renal transplantation (RT) is the treatment of choice for most patients with end-stage renal failure as this improves quality of life, survival and is cost-effective. ${ }^{1}$ The number of patients added to the waiting list each year for RT is increasing globally, whereas the number of RTs performed annually has remained relatively constant, which has resulted from the increasing demand of organs outstripping the supply. ${ }^{2}$ Despite significant advances in immunosuppressive and supportive therapies, several factors still compromise the long-term success of renal transplantation. ${ }^{3}$ Some of these factors are present at the time of transplantation in both donor and recipient, while others, in the form of complications, develop after RT. In this review, the main factors and events which influence the long-term graft function and the current practice to resolve these problems are discussed.

\section{PRETRANSPLANTATION FACTORS DONOR FACTORS}

Source: The source or donor strongly affects the longterm graft survival as the outcome following live donor (LD) RT is superior to that from cadaveric donors (CD). This has been confirmed by Hariharan et al. on analysis of 93,934 RTs performed in the United States between 1988 and 1996, where the one-year survival and halflife for grafts from LD and CD were 93.9 and 87.7 percent; and 21.6 and 13.8 years, respectively. ${ }^{4}$ The findings can not be attributed to better HLA matching as graft half-life of transplants between spouses, who

\section{Correspondence: \\ BM Shrestha \\ Sheffield Kidney Institute, Herries Road Sheffield S5 7AU, UK. \\ Email: shresthabm@doctors.net.uk}


are HLA-mismatched, is more than one-third better than CD grafts. ${ }^{5}$ The difference in outcome is due to several reasons. In CDs, the brain-stem death is associated with a cytokine storm leading to profound ischaemia and endothelial damage of peripheral organs. The ischaemia-reperfusion injury following cold-storage is less severe with LD kidney and so is the up regulation of cytokines and chemokines which favour over expression of HLA antigens by the endothelial and tubular epithelial cells, which increases the risk of acute and chronic rejection. ${ }^{6}$

Age: The poorer results of kidneys from elderly donors are mainly caused by the age-dependent progressive reduction of glomerular filtration rate and renal reserve, which is related to senescence. ${ }^{7}$ To overcome this problem, dual transplantation, that is, transplanting both kidneys from borderline donors to single recipients has been performed, but the results from various centres are not consistent. ${ }^{8}$ However, the current trend is to transplant kidney from elderly donors to an age matched recipients and this leads to best utilisation of the available kidneys. ${ }^{9}$

Sex: Women tend to have smaller kidneys with $17 \%$ fewer nephrons than male kidneys thereby affecting functional renal mass. The number of glomeruli per kidney as well as the mean glomerular volume closely correlates with kidney weight. The long-term survival of a graft from a female donor to a male recipient is significantly lower than other sex combinations. ${ }^{10}$

HLA mismatches: Human leucocyte antigen (HLA) molecules of the grafts are the principal targets of the immune response in transplantation. The clinical benefits of HLA matching on the graft survival are being appreciated in large registries even in the recent era of effective immunosuppressive regimens. HLA matched grafts have an estimated half-life of 12.4 years as compared with 8.6 years for HLA mismatched graft. ${ }^{11}$ In addition to HLA matching, cross-reactive group (CREG) matching is being increasingly emphasised as CREG matching is associated with a reduced frequency of late acute rejection episodes and improved graft function at 2 years. ${ }^{12}$ In the United Network of Organ Sharing (UNOS) database the risk of chronic rejection was $62 \%$ higher in CREG-mismatched recipients compared with those receiving a HLA- and CREG-matched kidney. ${ }^{13}$

\section{RECIPIENT FACTORS}

Age: Young age is associated with relatively high state of immune responsiveness to alloantigens and increased risk of acute rejection and this is compounded by noncompliance. ${ }^{14}$ This calls for more intense immunosuppression and vigilance. As the age advances, there is increased risk of death from cardiovascular diseases, malignancies and infectious complications related to over-immunosuppression. Death with a functioning graft is more common in elderly recipients, hence the importance of adequate screening prior to and a less aggressive immunosuppressive regimen following transplantation. ${ }^{15}$

Duration of dialysis treatment: The outcome of RT is adversely affected by the duration of dialysis pretransplantation the evidence is in favour of pre-emptive transplantation. ${ }^{16}$ Analysis from United States Renal Data System (USRDS) has shown transplantation of a kidney from a living donor without previous long-term dialysis was associated with a 52 percent reduction in the risk of allograft failure during the first year after transplantation $(P=0.002)$, an 82 percent reduction during the second year $(P=0.001)$, and an 86 percent reduction during subsequent years $(P=0.001)$, as compared with transplantation after dialysis. ${ }^{17}$ Using a paired donor kidney analysis, Meire-Kriesche et al. have demonstrated worse outcome with longer time on dialysis which was true for both CD and LD RTs. The time on dialysis remains the strongest modifiable factor influencing transplant outcome. ${ }^{18}$

Sensitisation (Anti-HLA antibodies): Patients with antiHLA antibodies elicited by pregnancies, blood transfusions, or failed transplants, despite negative cross-match at the time of transplantation, are at increased risk of acute and chronic rejections leading to graft loss. ${ }^{19}$ Antibodies to both HLA class I and class II antigens are detrimental and presence of donor-specific antibodies in particular, before or after transplantation, is associated with rejection and graft loss. However, transplant glomerulopathy may occur in the absence of demonstrable CD4 staining in the peritubular capillaries. ${ }^{20}$

\section{POSTRANSPLANTATION FACTORS}

SPECIFIC FACTORS AFFECTING GRAFT DYSFUNCTION Delayed graft function: Delayed graft function (DGF) is a common complication after cadaveric renal transplantation, and may affect graft function. ${ }^{21}$ Logistic regression analysis ( $N=8950$ ) of the data from the ongoing international, prospective; observational study, the Neoral-MOST (Multinational Observational Study in renal Transplantation), showed higher donor age, longer cold ischaemia time, male recipients, Caucasian 
recipients, high recipients body mass index, and panel reactive antibodies were all associated with a higher risk for DGF.22 Institution of less nephrotoxic immunosuppressive regimen and supportive therapy is mandatory.

Acute rejection: There has been a significant reduction in the incidence of acute rejection since the introduction of tacrolimus and mycophenolate mofetil, which according to recent report from USA had reduced from $43.5 \%$ in 1991 to $15.55 \%$ in $2000 .{ }^{23}$ The impact of acute rejection on long-term outcome depends on its time of occurrence (early or late), number (one or more), reversibility with steroid treatment (complete or partial), and the histological grade according to Banff criteria and on development of humoral antibodies. Sijpkens demonstrated that 10 year graft survival was $86 \%$ for patients who developed acute rejection by third posttransplant month and $45 \%$ for those who had rejection after three months. The humoral rejection is diagnosed by detecting $C D$ in the peritubular capillaries and/or presence of circulating donor specific antibodies and is treated with escalation of immunosuppression in addition to plasmapheresis, riruximab ${ }^{24}$ and intravenous immunoglobulin therapy. ${ }^{25-27}$

Viral infections: Over-immunosuppression leads to myriads of infectious complications post-transplantation. Of these, BK polyoma virus and cytomegalovirus (CMV) can lead to graft dysfunction and loss, if not diagnosed and treated early. ${ }^{28}$ BK virus, which remains latent in the urinary tract, can reactivate in patients treated with tacrolimus and mycophenolate mofetil (MMF) and present with progressive graft dysfunction. ${ }^{29}$ Diagnosis is established by detection of viral DNA by polymerase chain reaction and histological demonstration of cytopathic changes and inclusion bodies. Reduction of immunosuppression or replacement of tacrolimus and MMF with leflunomide, may rescue the kidney. ${ }^{30} \mathrm{CMV}$ infection is associated with acute rejection and chronic allograft dysfunction, which had led to significant development of strategies in prophylactic and pre-emptive therapy. ${ }^{31-33}$

Calcineurin inhibitors (CNI) nephrotoxicity: Chronic calcineurin inhibitors (tacrolimus and ciclosporin) nephrotoxicity is dose-dependent and manifests histologically with progressive glomerular sclerosis, arteriolopathy, interstitial fibrosis and tubular atrophy leading to progressive decline in renal function. ${ }^{34} \mathrm{CNI}$ reducing or sparing strategies have shown to be the way forward in reducing premature graft loss. ${ }^{35,36}$

Recurrence of primary disease: Recurrence of primary disease has remained an unresolved problem and leading to significant renal allograft loss Immunoglobulin-A nephritis, membranous nephropathy and lupus nephritis do not affect 10 year graft survival even if they have recurred in the graft. ${ }^{37}$ On the other hand, recurrence of focal segmental glomerulosclerosis, membranoproliferative glomerulonephritis, Henoch-Schonlein purpura and haemolytic uraemic syndrome will lead to graft loss, although sporadic cases of response to plasmapheresis and immunoadsorption have been reported. ${ }^{38,39}$

De novo glomerulonephritis may develop in the transplanted kidneys. Membranous nephropathy related to hepatitis-B and membranoproliferative glomerulonephritis related to hepatitis-c virus carriers are most frequent forms. However, de novo idiopathic membranous nephropathy, acute glomerulonephritis, minimal change nephropathy and collapsing focal glomerulosclerosis have been described. ${ }^{40}$

De novo thrombotic micrioangiopathy: De novo thrombotic microangiopathy may occur in patients on ciclosporin, tacrolimus, sirolimus and monoclonal antibodies (OKT3) presenting with features of haemolytic uraemic syndrome of graft dysfunction. Renal biopsy is indispensable for diagnosis. Withdrawal of offending agent and plasmapheresis have been successful in several studies. ${ }^{41}$

\section{NON-SPECIFIC FACTORS AFFECTING GRAFT DYSFUNCTION}

De novo diabetes: Up to $25 \%$ of $\mathrm{RT}$ recipient develop de novo diabetes related to immunosuppressive therapy, particularly due to steroids and tacrolimus, thereby increasing risk of cardiac, cerebrovascular and peripheral vascular disease. ${ }^{42}$ Steroid and $\mathrm{CNI}$ sparing regimens reduces this risk.

Arterial hypertension: Post-transplant hypertension, resulting from immunosuppressive agents, has significant influence on the long-term graft and patient survival, hence the importance of adequate control of blood pressure. ${ }^{43,44}$

Nephrotoxic agents: The inappropriate use of nephrotoxic agent such as aminoglycosides, flouroquinolones, nonsteroidal anti-inflammatory drugs, sulphonamides and contrast media causes dose-dependent toxicity and progressive graft dysfunction. Adequate hydration and infusion of $\mathrm{N}$-acetylcysteine prior to injection of radiological contrast media has shown to reduce nephrotoxicity. ${ }^{45}$

Non-compliance: Non-compliance to immunosuppressants 
in $\mathrm{RT}$ recipients is a major factor affecting graft survival, but it is difficult to detect accurately in clinical practice. In one study, poor compliance was recorded in $22 \%$ patients and in $36 \%$ of patients, graft loss was preceded by episodes of non-compliance. Meta-analysis of several studies has shown the odds of graft failure increased seven fold in non-compliant patients. ${ }^{46}$

\section{IMMUNOSUPPRESSIVE THERAPY}

The introduction of ciclosporin in $1980 \mathrm{~s}^{47,48}$, ciclosporin micro-emulsion (Neoral) ${ }^{49}$, tacrolimus ${ }^{50,51}$ and $\mathrm{MMF}^{52,53}$ in 1990s, sirolimus ${ }^{54}$ and anti-interleukin-2 receptor antibodies (basiliximab and daclizumab) ${ }^{55,56}$ recently has been associated with reduced incidence of acute rejection episodes during the first year after $\mathrm{RT}$. In a recent systematic review from Australia, the graft survival with tacrolimus was superior compared with ciclosporin, although individual randomized controlled trials (RCTs) had shown no difference in the past, ${ }^{57}$ Monitoring blood ciclosporin level at 2 hours post-dose (C2) significantly reduces the severity and incidence of acute rejection compared with 12 hours post-dose trough ( $\mathrm{CO}$ ) monitoring, without adverse consequences in terms of renal function or tolerability. ${ }^{58}$ Induction regimens using polyclonal antibodies (antithymocyte globulin) ${ }^{59}$, monoclonal antibodies (OKT3) ${ }^{60}$ and antiIL2 receptor antibodies in combination with combinations of above-mentioned drugs have been studied in several RCTs ${ }^{61}$ and all of them have been effective in reducing acute rejections, albeit with their individual side-effects. CNI sparing ${ }^{62}$ and steroid-free regimens ${ }^{63}$ have been evaluated. Reduction and possible withdrawal of $\mathrm{CNI}$ with either addition or continuation of MMF has slowed the rate of loss of renal function in patients with CAN. ${ }^{64}$ Everolimus (Certican) ${ }^{65}$, mycophenolate sodium (Myfortic)66, alemtuzumab (Campath $1 \mathrm{H})^{67,68}$, FTY-72069 are in various stages of trials showing promising results. ${ }^{70}$

\section{CHRONIC ALLOGRAFT NEPHROPATHY}

Chronic allograft nephropathy (CAN) is the leading cause of RT failure which presents clinically as progressive and irreversible deterioration of renal function, proteinuria and hypertension, and histologically with concentric arteriolosclerosis, glomerulosclerosis, tubular atrophy and interstitial fibrosis. ${ }^{3}$ Both immunological (late acute rejection, HLA-mismatches, sensitisation and non-compliance) and non-immunological factors (brain death, delayed graft function, infection, hyperlipidaemia, hypertension, smoking, donor age, donor sex, donor race and CNI toxicity) are implicated in the aetiology of CAN. ${ }^{71}$

There is no established treatment for CAN, mainly because of presence of irreversible damage at the time of diagnosis. ${ }^{72}$ Nevertheless, in early phases of disease, change in immunosuppressive agents to less nephrotoxic regimen consisting of MMF or sirolimus may stabilise or even reverse part of renal dysfunction. ${ }^{73-75}$ Belatacept, a selective costimulation blocker, is being shown to preserve the glomerular filtration rate and reduce the rate of CAN. Non-immunological interventions to decelerate the progression CAN include control of hypertension ${ }^{76}$, proteinuria ${ }^{77}$ and hyperlipidaemia. ${ }^{78}$ Significant reduction of proteinuria has been reported following the use of angiotensin converting enzyme inhibitors and angiotensin $\mathrm{II}$ receptor antagonists in clinical transplantation. ${ }^{79,80}$

\section{CONCLUSIONS}

Several factors present in the donor and recipients pretransplantation and events taking place posttransplantation described above influence the long-term outcome following RT. CAN is the leading cause of graft loss following RT and its prevention by modulation of the aetiological factors, early diagnosis and measures to halt the progression of CAN are paramount. A low threshold for biopsy helps to detect sub-clinical rejection and early changes of CAN. Least nephrotoxic and steroid sparing immunosuppressive regimens are the way forward in preservation of renal function in long-term.

\section{REFERENCES}

1. Wolfe RA, Ashby VB, Milford EL. Comparison of mortality in all patients on dialysis, patients on dialysis awaiting transplantation, and recipients of a first cadaveric transplant. N Engl J Med 1999; 341(23):1725-30.

2. Calne R. Clinical transplantation: current problems, possible solutions. Philos Trans R Soc Lond B Biol Sci 2005; 360(1461):1797-801.

3. Paul LC. Chronic allograft nephropathy: An update. Kidney Int 1999; 56(3):783-93.

4. Hariharan S, Johnson CP, Bresnahan BA. Improved graft survival after renal transplantation in the United States, 1988 to 1996. N Engl J Med 2000; 342(9):605-12.

5. Gjertson DW, Cecka JM. Living unrelated donor kidney transplantation. Kidney Int 2000; 58(2):491-9.

6. Koo DD, Welsh KI, McLaren AJ. Cadaver versus living donor kidneys: impact of donor factors on antigen induction before transplantation. Kidney Int 1999; 56(4):1551-9.

7. Halloran PF, Melk A, Barth C. Rethinking chronic allograft nephropathy: the concept of accelerated senescence. J Am Soc Nephrol 1999; 10(1):167-81. 
8. Bunnapradist S, Gritsch HA, Peng A. Dual kidneys from marginal adult donors as a source for cadaveric renal transplantation in the United States. J Am Soc Nephrol 2003; 14(4):1031-6.

9. Fritsche L, Horstrup J, Budde K. Old-for-old kidney allocation allows successful expansion of the donor and recipient pool. Am J Transplant 2003; 3(11):1434-9.

10. Kwon OJ, Kwak JY, Kang CM. The impact of gender and age matching for long-term graft survival in living donor renal transplantation. Transplant Proc 2005; 37(2):726-8.

11. Opelz G, Wujciak T, Dohler B. HLA compatibility and organ transplant survival. Collaborative Transplant Study. Rev Immunogenet 1999; 1(3):334-42.

12. Sijpkens YW, Doxiadis, II, Mallat MJ. Early versus late acute rejection episodes in renal transplantation. Transplantation 2003; 75(2):204-8.

13. Wujciak T, Opelz G. Evaluation of HLA matching for CREG antigens in Europe. Transplantation 1999; 68(8):1097-9.

14. Raiz LR, Kilty KM, Henry ML, Ferguson RM. Medication compliance following renal transplantation. Transplantation 1999; 68(1):51-5.

15. Segoloni GP, Messina M, Giraudi R. Renal transplantation in patients over 65 years of age: no more a contraindication but a growing indication. Transplant Proc 2005; 37(2):721-5.

16. Cecka JM. The OPTN/UNOS Renal Transplant Registry 2003. Clin Transpl 2003:1-12.

17. Mange KC, Joffe MM, Feldman HI. Effect of the use or nonuse of long-term dialysis on the subsequent survival of renal transplants from living donors. N Engl J Med 2001; 344(10):726-31.

18. Meier-Kriesche HU, Kaplan B. Waiting time on dialysis as the strongest modifiable risk factor for renal transplant outcomes: a paired donor kidney analysis. Transplantation 2002; 74(10):1377-81.

19. McKenna RM, Takemoto SK, Terasaki PI. Anti-HLA antibodies after solid organ transplantation. Transplantation 2000; 69(3):319-26.

20. Akalin E, Dinavahi R, Dikman S. Transplant glomerulopathy may occur in the absence of donor-specific antibody and C4d staining. Clin J Am Soc Nephrol 2007; 2(6):1261-7.

21. Sola R, Alarcon A, Jimenez C, Osuna A. The influence of delayed graft function. Nephrol Dial Transplant 2004; 19 Suppl 3:32-7.

22. Lebranchu Y, Halimi JM, Bock A. Delayed graft function: risk factors, consequences and parameters affecting outcomeresults from MOST, A Multinational Observational Study. Transplant Proc 2005; 37(1):345-7.

23. Keith DS, DeMattos A, Golconda M. Factors associated with improvement in deceased donor renal allograft function in the 1990s. J Am Soc Nephrol 2005; 16(5):1512-21.

24. Steinmetz OM, Lange-Husken F, Turner JE. Rituximab removes intrarenal B cell clusters in patients with renal vascular allograft rejection. Transplantation 2007; 84(7):842-
50.

25. Racusen LC, Solez K, Colvin RB. The Banff 97 working classification of renal allograft pathology. Kidney Int 1999; 55(2):713-23.

26. Shah A, Nadasdy T, Arend L. Treatment of C4d-positive acute humoral rejection with plasmapheresis and rabbit polyclonal antithymocyte globulin. Transplantation 2004; 77(9):1399-405.

27. Lehrich RW, Rocha PN, Reinsmoen N. Intravenous immunoglobulin and plasmapheresis in acute humoral rejection: experience in renal allograft transplantation. Hum Immunol 2005; 66(4):350-8.

28. Shrestha BM, Parton D, Gray A. Cytomegalovirus involving gastrointestinal tract in renal transplant recipients. Clin Transplant 1996; 10(2):170-5.

29. Drachenberg CB, Beskow CO, Cangro CB. Human polyoma virus in renal allograft biopsies: morphological findings and correlation with urine cytology. Hum Pathol 1999; 30(8):9707.

30. Williams JW, Javaid B, Kadambi PV. Leflunomide for polyomavirus type BK nephropathy. N Engl J Med 2005; 352(11):1157-8.

31. Reischig T, Jindra P, Mares J. Valacyclovir for cytomegalovirus prophylaxis reduces the risk of acute renal allograft rejection. Transplantation 2005; 79(3):317-24.

32. Opelz G, Dohler B, Ruhenstroth A. Cytomegalovirus prophylaxis and graft outcome in solid organ transplantation: a collaborative transplant study report. Am J Transplant 2004; 4(6):928-36.

33. Ahmed J, Velarde C, Ramos M. Outcome of low-dose ganciclovir for cytomegalovirus disease prophylaxis in renaltransplant recipients. Transplantation 2004; 78(11):1689-92.

34. Cantarovich D, Vistoli F, Soulillou JP. Immunosuppression minimization in kidney transplantation. Front Biosci 2008; 13:1413-32.

35. Takeda A, Uchida K, Haba T. Chronic cyclosporin nephropathy: long-term effects of cyclosporin on renal allografts. Clin Transplant 2001; 15 Suppl 5:22-9.

36. Weir MR. Methods and outcomes of calcineurin inhibitor reduction or withdrawal in patients with chronic allograft nephropathy after the first year posttransplantation. Transplant Proc 2001; 33(4 Suppl):19S-28S.

37. Ostrowska J, Pazik J, Lewandowski Z. Posttransplantation glomerulonephritis: risk factors associated with kidney allograft loss. Transplant Proc 2007; 39(9):2751-3.

38. Briganti EM, Russ GR, McNeil JJ. Risk of renal allograft loss from recurrent glomerulonephritis. N Engl J Med 2002; 347(2):103-9.

39. Ponticelli C, Campise M, Tarantino A. The different patterns of response to plasmapheresis of recurrent focal and segmental glomerulosclerosis. Transplant Proc 2002; 34(8):3069-71.

40. Schwarz A, Krause PH, Offermann G, Keller F. Recurrent 
and de novo renal disease after kidney transplantation with or without cyclosporine A. Am J Kidney Dis 1991; 17(5):52431.

41. Schwimmer J, Nadasdy TA, Spitalnik PF. De novo thrombotic microangiopathy in renal transplant recipients: a comparison of hemolytic uremic syndrome with localized renal thrombotic microangiopathy. Am J Kidney Dis 2003; 41(2):471-9.

42. Schiel R, Heinrich S, Steiner T. Post-transplant diabetes mellitus: risk factors, frequency of transplant rejections, and long-term prognosis. Clin Exp Nephrol 2005; 9(2):164-9.

43. Kasiske BL, Anjum S, Shah R. Hypertension after kidney transplantation. Am J Kidney Dis 2004; 43(6):1071-81.

44. Opelz G, Dohler B. Improved long-term outcomes after renal transplantation associated with blood pressure control. Am J Transplant 2005; 5(11):2725-31.

45. Kandzari DE, Rebeiz AG, Wang A, Sketch MH, Jr. Contrast nephropathy : an evidence-based approach to prevention. Am J Cardiovasc Drugs 2003; 3(6):395-405.

46. Butler JA, Peveler RC, Roderick P. Measuring compliance with drug regimens after renal transplantation: comparison of self-report and clinician rating with electronic monitoring. Transplantation 2004; 77(5):786-9.

47. Merion RM, White DJ, Thiru S. Cyclosporine: five years' experience in cadaveric renal transplantation. N Engl J Med 1984; 310(3):148-54.

48. Kahan BD, Mickey R, Flechner SM. Multivariate analysis of risk factors impacting on immediate and eventual cadaver allograft survival in cyclosporine-treated recipients. Transplantation 1987; 43(1):65-70.

49. Curtis JJ, Lynn M, Jones PA. Neoral conversion from Sandimmune in maintenance renal transplant patients: an individualized approach. J Am Soc Nephrol 1998; 9(7):1293300.

50. Mayer AD, Dmitrewski J, Squifflet JP. Multicenter randomized trial comparing tacrolimus (FK506) and cyclosporine in the prevention of renal allograft rejection: a report of the European Tacrolimus Multicenter Renal Study Group. Transplantation 1997; 64(3):436-43.

51. Margreiter R. Efficacy and safety of tacrolimus compared with ciclosporin microemulsion in renal transplantation: a randomised multicentre study. Lancet 2002; 359(9308):7416.

52. Mathew TH. A blinded, long-term, randomized multicenter study of mycophenolate mofetil in cadaveric renal transplantation: results at three years. Tricontinental Mycophenolate Mofetil Renal Transplantation Study Group. Transplantation 1998; 65(11):1450-4.

53. David KM, Morris JA, Steffen BJ. Mycophenolate mofetil vs. azathioprine is associated with decreased acute rejection, late acute rejection, and risk for cardiovascular death in renal transplant recipients with pre-transplant diabetes. Clin Transplant 2005; 19(2):279-85.

54. Kahan BD, Julian BA, Pescovitz MD. Sirolimus reduces the incidence of acute rejection episodes despite lower cyclosporine doses in caucasian recipients of mismatched primary renal allografts: a phase II trial. Rapamune Study Group. Transplantation 1999; 68(10):1526-32.

55. Parrott NR, Hammad AQ, Watson CJ. Multicenter, randomized study of the effectiveness of basiliximab in avoiding addition of steroids to cyclosporine a monotherapy in renal transplant recipients. Transplantation 2005; 79(3):3448.

56. Morris JA, Hanson JE, Steffen BJ. Daclizumab is associated with decreased rejection and improved patient survival in renal transplant recipients. Clin Transplant 2005; 19(3):3405 .

57. Webster AC, Woodroffe RC, Taylor RS. Tacrolimus versus ciclosporin as primary immunosuppression for kidney transplant recipients: meta-analysis and meta-regression of randomised trial data. Bmj 2005; 331(7520):810.

58. Nashan B, Bock A, Bosmans JL. Use of Neoral C monitoring: a European consensus. Transpl Int 2005; 18(7):768-78.

59. Goggins WC, Pascual MA, Powelson JA. A prospective, randomized, clinical trial of intraoperative versus postoperative Thymoglobulin in adult cadaveric renal transplant recipients. Transplantation 2003; 76(5):798-802.

60. Thistlethwaite JR, Jr., Heffron TG, Stuart JK. Selective OKT3 induction therapy in adult cadaveric-donor renal transplant recipients. Am J Kidney Dis 1989; 14(5 Suppl 2):28-34.

61. Bunnapradist S, Hong A, Lee B, Takemoto SK. Multivariate analysis of the effectiveness of using antibody induction therapy according to the degree of HLA mismatches. Transplant Proc 2005; 37(2):886-8.

62. Velosa JA, Larson TS, Gloor JM, Stegall MD. Cyclosporine elimination in the presence of TOR inhibitors: effects on renal function, acute rejection, and safety. Am J Kidney Dis 2001; 38(4 Suppl 2):S3-S10.

63. Augustine JJ, Hricik DE. Steroid sparing in kidney transplantation: changing paradigms, improving outcomes, and remaining questions. Clin J Am Soc Nephrol 2006; 1(5):1080-9.

64. Rama I, Cruzado JM, Gil-Vernet S. Steroids can be safely withdrawn from cyclosporine and mycophenolate mofetiltreated renal allograft recipients: long-term results. Transplantation 2005; 80(2):164-8.

65. Pascual J, Marcen R, Ortuno J. Clinical experience with everolimus (Certican): optimizing dose and tolerability. Transplantation 2005; 79(9 Suppl):S80-4.

66. Massari P, Duro-Garcia V, Giron F. Safety assessment of the conversion from mycophenolate mofetil to enteric-coated mycophenolate sodium in stable renal transplant recipients. Transplant Proc 2005; 37(2):916-9.

67. Watson CJ, Bradley JA, Friend PJ. Alemtuzumab (CAMPATH $1 \mathrm{H})$ induction therapy in cadaveric kidney transplantation-efficacy and safety at five years. Am J Transplant 2005; 5(6):1347-53. 
68. Knechtle SJ, Fernandez LA, Pirsch JD. Campath-1H in renal transplantation: The University of Wisconsin experience. Surgery 2004; 136(4):754-60.

69. Tedesco-Silva H, Mourad G, Kahan BD. FTY720, a novel immunomodulator: efficacy and safety results from the first phase 2A study in de novo renal transplantation. Transplantation 2005; 79(11):1553-60.

70. Delbridge MS, Shrestha BM, Raftery AT. Reduction of ischemia-reperfusion injury in the rat kidney by FTY720, a synthetic derivative of sphingosine. Transplantation 2007; 84(2):187-95.

71. Sijpkens YW, Doxiadis, II, van Kemenade FJ. Chronic rejection with or without transplant vasculopathy. Clin Transplant 2003; 17(3):163-70.

72. Montagnino G, Banfi G, Campise MR. Impact of chronic allograft nephropathy and subsequent modifications of immunosuppressive therapy on late graft outcomes in renal transplantation. Nephrol Dial Transplant 2004; 19(10):26229.

73. Dudley C, Pohanka E, Riad H. Mycophenolate mofetil substitution for cyclosporine a in renal transplant recipients with chronic progressive allograft dysfunction: the "creeping creatinine" study. Transplantation 2005; 79(4):466-75.

74. Tang SC, Chan KW, Tang CS. Conversion of ciclosporin A to tacrolimus in kidney transplant recipients with chronic allograft nephropathy. Nephrol Dial Transplant 2006; 21(11):3243-51.

75. Bumbea V, Kamar N, Ribes D. Long-term results in renal transplant patients with allograft dysfunction after switching from calcineurin inhibitors to sirolimus. Nephrol Dial Transplant 2005; 20(11):2517-23.

76. Premasathian NC, Muehrer R, Brazy PC. Blood pressure control in kidney transplantation: therapeutic implications. J Hum Hypertens 2004; 18(12):871-7.

77. Ramanathan V, Suki WN, Rosen D, Truong LD. Chronic allograft nephropathy and nephrotic range proteinuria. Clin Transplant 2005; 19(3):413-7.

78. Holdaas H. Preventing cardiovascular outcome in patients with renal impairment: is there a role for lipid-lowering therapy? Am J Cardiovasc Drugs 2005; 5(4):255-69.

79. Zaltzman JS, Nash M, Chiu R, Prasad R. The benefits of renin-angiotensin blockade in renal transplant recipients with biopsy-proven allograft nephropathy. Nephrol Dial Transplant 2004; 19(4):940-4.

80. Halimi JM, Giraudeau B, Buchler M. Enalapril/amlodipine combination in cyclosporine-treated renal transplant recipients: a prospective randomized trial. Clin Transplant $2007 ; 21(2): 277-84$. 